\title{
Linfocentros del miembro pelviano del "carpincho" (Hydrochoerus hydrochaeris, Linnaeus 1766)
}

\author{
Bode, F.F.; Cao, J.A.; Resoagli, J.M.; Millán, S.G. \\ Cátedra de Anatomía Comparada Primera Parte, Facultad de Ciencias Veterinarias, UNNE, Sargento Cabral \\ 2139, Corrientes (3400), Argentina. Tel 03783-425753, E-mail: anato1@vet.unne.edu.ar.
}

\begin{abstract}
Resumen
Bode, F.F.; Cao, J.A.; Resoagli, J.M.; Millán, S.G.: Linfocentros del miembro pelviano del "carpincho" (Hydrochoerus hydrochaeris, Linnaeus 1766). Rev. vet. 22: 1, 72-73, 2011. El presente trabajo forma parte de un proyecto cuyo objetivo es estudiar la anatomía del sistema linfático del carpincho (Hydrochoerus hydrochaeris). En esta comunicación se aborda el número, forma y tamaño de los linfocentros del miembro pelviano, así como sus relaciones con las estructuras vecinas. Se disecaron diez cadáveres de carpinchos y los hallazgos se documentaron fotográficamente. En la región descripta se localizaron los nódulos linfáticos inguinal superficial, inguinal profundo y subilíaco o prefemoral. La disposición de estos linfonódulos es semejante a la descripta para la especie porcina. El conocimiento de la situación de los linfonódulos asume utilidad al momento de valorar la aptitud de la carne de H. hydrochaeris destinada al consumo humano.
\end{abstract}

Palabras clave: Hydrochoerus hydrochaeris, anatomía, linfocentros, miembro pelviano.

\begin{abstract}
Bode, F.F.; Cao, J.A.; Resoagli, J.M.; Millán, S.G.: Lymphocenters of the pelvic limb of “capybara” (Hydrochoerus hydrochaeris, Linnaeus 1766). Rev. vet. 22: 1, 72-73, 2011. Aim of this study is to report the anatomy of the lymphatic system of the capybara (Hydrochoerus hydrochaeris). The number, shape and size of the lymphocenters of the pelvic limb, as well as their topographical relations with the neighboring structures, are presented. Ten cadaveric preparations were dissected and findings were registered photographically. Superficial, deep and subiliac (prefemoral) lymph nodes were present. The disposition of these lymphocenters is similar to that of the porcine species. The location of lymphocenters is useful to evaluate the aptitude of the meat of $H$. hydrochaeris destined to human consumption.
\end{abstract}

Key words: Hydrochoerus hydrochaeris, anatomy, lymphocenters, pelvic member.

\section{INTRODUCCIÓN}

El conocimiento del sistema linfático reviste particular interés en mamíferos domésticos y silvestres por la importancia que adquiere en la inspección de las carnes para el consumo ${ }^{1}$. La bibliografía consultada sobre anatomía de Hydrochoerus hydrochaeris brinda descripciones sobre las estructuras de los órganos contenidos en las cavidades abdominal y pelviana ${ }^{3,4}$, no habiéndose hallado datos sobre la situación anatómica de los linfonódulos. Tal conocimiento asume importancia bromatológica al facilitar el control de la higiene y sanidad de los alimentos, especialmente en la inspección de los productos de la caza ${ }^{2,5}$. El objetivo del presente trabajo fue conocer la situación, forma, tamaño y relaciones de los nódulos linfáticos de la región inguinal y miembro pelviano de carpinchos.

\section{MATERIAL Y MÉTODOS}

Se utilizaron 10 cadáveres de $H$. hydrochaeris, procedentes del Criadero Experimental de Carpinchos INTA-Mercedes (Corrientes). Se realizó sangría blanca e inyección de solución de formol al 10\% para lograr la fijación in situ, tras lo cual se practicó necropsia según técnica habitual.

Con el animal en decúbito lateral, se desplazó la piel y se disecaron las diferentes estructuras de la región. Los linfocentros fueron valorados en número, forma, tamaño y relaciones con las estructuras vecinas. Los datos se obtuvieron por observación directa de los preparados anatómicos y mediciones con regla milimetrada. Los valores obtenidos fueron procesados estadísticamente para obtener media aritmética y desviación estándar. Los hallazgos fueron documentados fotográficamente. 


\section{RESULTADOS Y DISCUSIÓN}

Las disecciones realizadas permitieron observar la siguiente disposición de linfonódulos:

Nódulo linfático inguinal superficial (Figura 1). Se lo observó como un linfonódulo alargado, de forma ovoide, de 15,3 $\pm 0,8 \mathrm{~mm}$ de largo y $10,43 \pm 0,7 \mathrm{~mm}$ de ancho, color grisáceo, de superficie lisa, situado en la región inguinal, entre la túnica flava y la piel, en lateral del orificio inguinal superficial y del cordón espermático, cubierto por tejido adiposo.

Nódulo linfático inguinal profundo (Figura 2). Se trató de una cadena de 4 a 5 pequeños nódulos de color grisáceo y superficie lisa, ubicados en el trayecto de los vasos femorales profundos a nivel del anillo crural del canal femoral, cubiertos por la fascia femoral.

Nódulo linfático subilíaco o prefemoral (Figuras 2 y 3). Se verificó la existencia de 2 linfocentros, uno derecho y otro izquierdo, situados sobre el borde craneal del músculo tensor de la fascia lata, ligeramente desplazados hacia medial en un punto equidistante entre el tubérculo coxal y la patela. El linfonódulo derecho ostentó una forma circular y midió $10,33 \pm 0,76$ $\mathrm{mm}$ de largo por $10,43 \pm 0,7 \mathrm{~mm}$ de ancho. El izquierdo reveló una forma alargada, de 20,6 $\pm 1,5 \mathrm{~mm}$ de largo y $0,03 \pm 1,75 \mathrm{~mm}$ de ancho.

Atento al número, forma, tamaño y relaciones con las estructuras vecinas, se concluye que los nódulos linfáticos de $H$. hydrochaeris se asemejan a los del resto de los animales domésticos, en coincidencia con las descripciones realizadas por los autores clásicos ${ }^{1}$, aunque advirtiendo la ausencia del nódulo poplíteo descrito en otras especies.

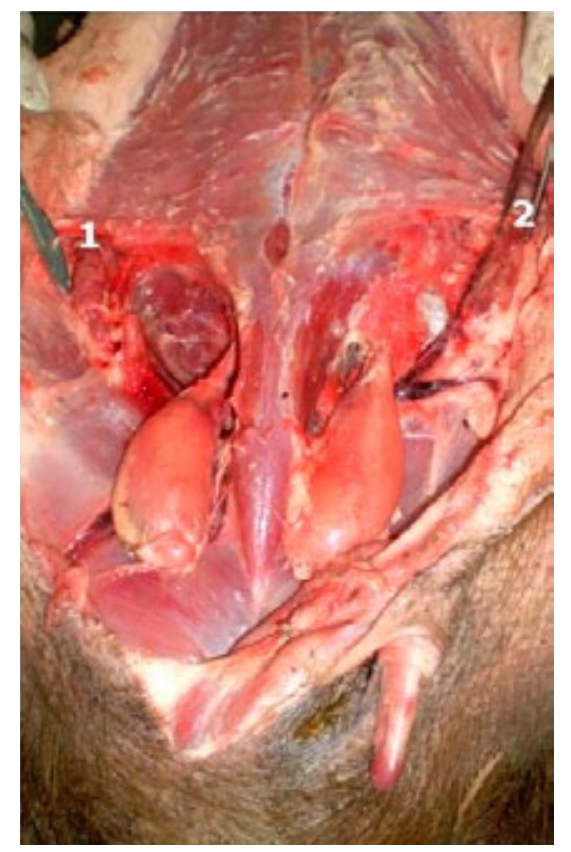

Figura 1. Nódulo linfático inguinal superficial (1: derecho, 2: izquierdo).

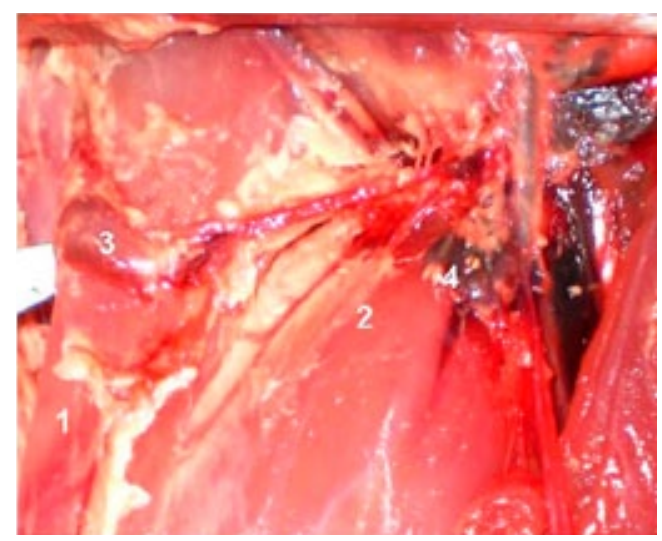

Figura 2. Nódulo linfático inguinal profundo (4), nódulo linfático subilíaco o prefemoral (3), canal femoral (2), músculo tensor de la fascia lata (1).

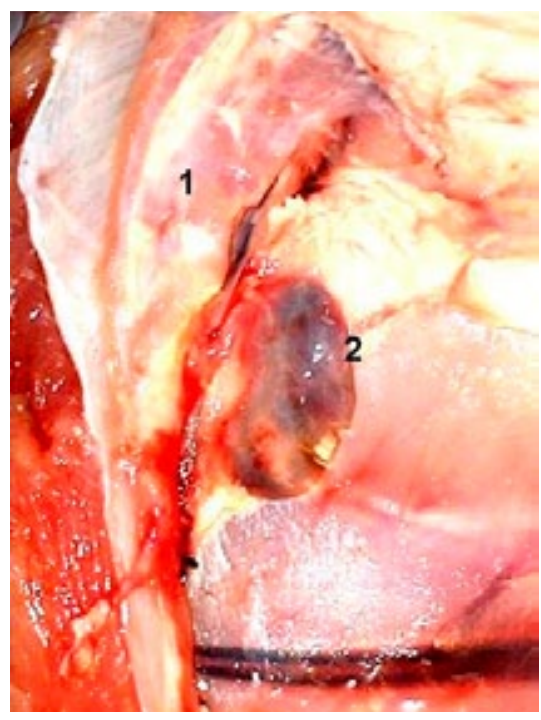

Figura 3. Nódulo linfático subilíaco o prefemoral (2), músculo tensor de la fascia lata (1).

\section{REFERENCIAS}

1. Getty R. 1982. Anatomía de los animales domésticos, $5^{\mathrm{a}}$ ed., Interamericana, México, p. 1481-1486.

2. Mayer HF. 1984. Bromatología, Ed. Impresiones UNNE, Resistencia (Argentina), p. 46-83.

3. Mendoza TH. 1977. Tórax del chigüire (Hydrochoerus hydrochaeris hydrochaeris), cavidad, análisis y topografía de órganos, trayectos vasculonerviosos. Trabajo de Ascenso, Universidad Central de Venezuela, $45 \mathrm{p}$.

4. Ojasti J. 1973. Estudio biológico del chigüire o capiba$r a$, Ed. Fondo Nacional de Investigaciones Agropecuarias, Caracas (Venezuela), $27 \mathrm{p}$.

5. SENASA. 1968. Reglamento de inspección de productos, subproductos y derivados de origen animal (Decreto Ley 4238/68, República Argentina). On line: www.senasa.gov. ar/archivos/File/ File753-capitulos.pdf. 